\title{
Microscopist 2
}

National Cancer Institute

\section{Source}

National Cancer Institute. Microscopist 2. NCI Thesaurus. Code C132422.

The second in a series of microscopists that are performing an assessment. 